\title{
Com(ple)menting the news on the financial crisis: The contribution of news users' commentary to the diversity of viewpoints in the public debate
}

European Journal of Communication 2014, Vol. 29(5) 529-548

(C) The Author(s) 2014 Reprints and permissions: sagepub.co.uk/journalsPermissions.nav DOI: |0.1 |77/0267323 | |4538724 ejc.sagepub.com

@SAGE

\section{Christian Baden and Nina Springer}

Ludwig Maximilian University Munich, Germany

\begin{abstract}
Does news users' commentary contribute to widening the diversity of viewpoints represented in the news? This article comparatively analyses the interpretations of the current financial crisis in the online coverage of five German newspapers and the subsequent commentary of news users. Using an innovative strategy to identify the interpretative repertoires constructed by news and user frames, it assesses how user commentary deviates from those viewpoints represented in the news. Findings show that user accounts mostly remain within the wider interpretative repertoires offered by the media. However, they utilize media frame fragments rather freely to construct their own views, shifting focus and elaborating upon new aspects. While no consistent alternative repertoires were constructed, users thus valuably complemented the diversity of concerns discussed on news websites.
\end{abstract}

\section{Keywords}

Audience research, content analysis, journalism, news/information, political communication, semiology/language/discourse

Media audiences crucially depend on journalists for forming political opinions, but are provided with only a constrained diet of (mostly official) viewpoints (Bennett, 1996; Hayes and Guardino, 2010). Due to the rise of social media enabling user commentary

\footnotetext{
Corresponding author:

Christian Baden, Institute for Communication Science \& Media Research (IfKW), Ludwig Maximilian University Munich, Oettingenstr. 67, 80538 München, Germany.

Email: baden@ifkw.Imu.de
} 
on online news platforms, news users are now able to directly complement the news with their own interpretations, thereby potentially raising the diversity of viewpoints available to the news audience (Carpenter, 2010; Springer, 2014). This article analyses the interpretations of the current public debt crisis in the online coverage of five newspapers and the subsequent commentary of news users: Do user comments elaborate on journalistic repertoires in the crisis, adding further information (Gamson, 1992)? Do they complement them with new perspectives, challenging the presented views (Springer and Pfaffinger, 2012)? Or do they mostly echo the limited variety of crisis interpretations present in the news (Iyengar and Simon, 1993; Tewksbury et al., 2000)?

This article uses an innovative strategy for assessing the diversity of interpretative repertoires (Wetherell and Potter, 1988), building upon existing measures of ideological and frame diversity (Benson, 2009; Hayes and Guardino, 2010; Voakes et al., 1996). The article empirically evaluates the democratic potential of social media contents for augmenting public political discourse in the financial crisis, and provides new insights into the interpretative resources mobilized by professional and lay communicators (Gamson, 1992).

\section{Theory}

\section{Journalistic diversity}

Providing the public with diverse interpretations is one key function performed by journalistic mass media (Ferree et al., 2002; Habermas, 1991). Different frames highlight different aspects of a situation, construct different interpretations and imply different evaluative judgments and suitable courses of action (Chong and Druckman, 2007; De Vreese, 2004). Particularly in high-stakes situations such as economic crises, diverse news frames are essential for enabling an informed, responsible and democratic political debate and economic behaviour, and to prevent dangerous misjudgements with potentially far-reaching consequences.

In consequence, the recurrent finding that journalism fails to fully represent the spectrum of relevant interpretations is cause for severe criticism (e.g. Herman and Chomsky, 1988). In the current financial crisis, allegations ranged from misrepresenting important causes and impacts of the crisis, to inadvertently fuelling the crisis by raising irrational fears, and advancing questionable solution strategies. The finding that journalism often represents only a limited diversity of viewpoints takes three basic forms in the literature. First, many content-analytic studies have traced the range of sources and, less frequently, the range of frames (see below) quoted in the news coverage on controversial issues (Althaus et al., 1996; Bennett, 1996; Benson, 2009; Benson and Hallin, 2007; Hayes and Guardino, 2010; Van Gorp, 2005; Zaller and Chiu, 1996). With regard to speakers, official sources (governments, administrations, foreign officials) occupy the lion's share of news coverage (Althaus et al., 1996; Bennett, 1996), and if non-elite sources are cited, the bulk of references is distributed over a small number of activist organizations widely recognized as 'counter' elites (Smith et al., 2001). Lay voices are occasionally referenced, but mostly serve to illustrate elite viewpoints, or are marginalized in other ways (Dardis, 2009; Hayes and Guardino, 2010). This approach generally assumes that 
different news sources provide diverse viewpoints (e.g. Voakes et al., 1996). However, diverse sources may share common interpretations, even if they disagree on the political positions taken (Snow and Benford, 1992). Diverse sources are likely to provide diverse interpretations, but no valid indicator for the presence of diverse views. Journalistic indexing of elite views justifies the suspicion that important viewpoints may be eclipsed, but it neither demonstrates that point, nor does including additional voices necessarily redress it (Bennett, 1996). A plurality of aspects may also be highlighted by just one source (Benford, 1993).

Among those studies that gauge the range of frames provided on an issue, most find that often no more than two or three frames suffice to capture the bulk of news reporting on an issue (e.g. Benson and Hallin, 2007; Bronstein, 2005; Carpenter, 2010; Hayes and Guardino, 2010; Van Gorp, 2005). However, this finding depends strongly on the definition of frames (Baden, 2010): Studies operationalizing frames at a high level of abstraction typically find that few major interpretations are competing with one another (e.g. Böcking, 2009; Van Gorp, 2005). More detailed frame studies usually find that advanced interpretations vary considerably over time (Baumgartner et al., 2008; Motta and Baden, 2013; Wessler, 1999). It remains unclear what, then, is the correct level of abstraction for distinguishing diverse interpretations (Baden, 2010; Donati, 1992): Too much abstraction subsumes meaningful diversity within one category of frames; too detailed strategies, by contrast, fail to distinguish between frames that formulate commensurable interpretations, and frames introducing contrasting viewpoints (Donati, 1992).

A second category of studies has probed the diversity of journalistic reporting by focussing on the representation of specific elite or alternative viewpoints (e.g. Ryan et al., 1998; Van Zoonen, 1992). Those studies reveal a strong, self-perpetuation bias: Views already salient in the news tend to remain there and crowd out marginal viewpoints. Novel perspectives are admitted hesitantly, and often only temporarily (Van Zoonen, 1992) - typically as the consequence of long-term frame-building efforts (Snow and Benford, 1992) aided by salient, newsworthy events (Ryan et al., 1998). Alternative frame advocates may (temporarily or even durably) gain counter-elite status in the journalistic source network; however, only few such counter-elites are recognized at a time. These studies demonstrate that diversity in the news is constrained by inert patterns of privileged relations between the media and selected political and social groups, upheld by various exclusionary biases in journalistic production (Andrews and Caren, 2010; Hutchins and Lester, 2006). However, these studies provide no measure of the overall diversity represented.

The final category of studies addresses those factors governing the journalistic production of diversity in the news (e.g. Benson and Hallin, 2007; Reese et al., 1994; Scheufele, 2006). Among the most important influences, these studies list (1) journalists' strong reliance on elite actors and established source networks (Althaus et al., 1996); (2) the balance norm in journalism, resulting in the indexing of binarily (or few) opposing positions (Bennett, 1996; Gerhards and Schäfer, 2010); (3) the pro-active frame-setting by few resourceful communicators (Böcking, 2009; Hutchins and Lester, 2006); (4) the scarcity of resources (specifically, time and money) available for thorough journalistic research (Gamson and Modigliani, 1987; 
Gandy, 1982); (5) the influence of co-orientation and validation through co-reference in mainstream public discourse (Reese et al., 1994); and (6) the formation of journalistic frames, which colour journalists' own perceptions of social issues (Scheufele, 2006). Among these, the balance norm produces at least limited diversity, as journalists occasionally seek or construct counter-elites where no opposing viewpoint is offered by established sources (Gerhards and Schäfer, 2010). In addition, the news factor of 'surprise'/'unexpectedness' sometimes admits deviant perspectives to the coverage (Galtung and Ruge, 1965). In sum, however, the overwhelming majority of influences points towards a limitation of plurality to no more than two or few contrasting and self-perpetuating views.

\section{Expectations for the diversity in the news and user commentary}

Recognizing these limiting factors, many scholars have hailed interactive platforms as venues for more diverse public debates (e.g. Bruns, 2005; Bruns et al., 2012; Carpenter, 2010; Graham, 2009; Savigny, 2002). Social media are open to carry any kind of viewpoint: No further selection process is applied before publication, such that an interested audience can easily gain access to a huge variety of relevant (and other) interpretations (Bowman and Willis, 2003; Bruns, 2005; Rosen, 2006). In this context, a particularly interesting development is the opening of commentary space on online news web pages (Singer et al., 2011; Springer, 2014). This format shares with news media the wide reach towards audiences interested in the news, but not necessarily looking for alternative viewpoints (Springer, 2014). Online news commentary thus holds the potential to increase the diversity of viewpoints represented in the public debate beyond small, active, or like-minded online audiences (Garrett, 2009), also raising journalists' awareness of other relevant views.

However, constructing alternative viewpoints is not easy, specifically in crises: where Journalists and commenters are challenged to make sense of a highly complex, novel, 'non-closed', and fast-evolving situation (Motta and Baden, 2013; Tenenboim-Weinblatt, 2008). From a news user's point of view, the unobtrusive and technical nature of certain aspects of the public debt crisis emphasizes commentators' dependence on media reporting, and the experts cited therein (Graber, 1988; Neuman et al., 1992). Also, as reactions to news coverage, user commentary is inevitably influenced by the information and frames provided therein (Baden, 2010; Reese, 2010). However, many of the crisis' impacts can be directly observed, legitimizing the use of experiential knowledge. Also, several mechanisms and policy solutions can be grasped based on popular wisdom (e.g. about housekeeping) and by drawing analogies to prior financial and other crises (Gamson et al., 1992; Graber, 1988; Graham, 2009). In addition, the far-reaching domestic implications of crisis policy measures provide fertile ground for politicization and contention, motivating users to mobilize diverse background knowledge (Baden, 2010; Schaap, 2009) and formulate deviant interpretations (Springer, 2014). The wide range of NGOs and professionals with stakes in the crisis enables numerous non-elite 'experts' to challenge official views. News users can make full use of the varied interpretative resources to construct widely diverse interpretations - at least of the obtrusive sides of the crisis. 


\section{Method}

\section{Data}

We conducted a content analysis of online news coverage and user commentary on selected key events during the European debt crisis. We identified five controversial moments during the political treatment of the crisis in 2012: The second Greek rescue package (21 February), the European fiscal pact (01 March), the Spanish bank aid program (27 June, 20 July), and the European Stability Mechanism (29 June). We sampled five influential German newspapers' online news sites representing the political left-right spectrum as well as highbrow, magazine, and tabloid journalism (Süddeutsche Zeitung, Die Welt, TZ, Die Zeit, Spiegel). From each web site, we obtained eight articles related to the selected events that were most prominently ranked and retrieved all posted user comments (on average, 100.4 comments per article on Zeit Online, 179.3 on Welt Online, 51.4 on Süddeutsche.de, 132.4 on Spiegel Online, and 12.0 on $T Z$ München). For analysis, we only considered the first five and last five user comments posted in response to each article (10 comments per article). As there were only few comments per article on $T Z$, we included a ninth article to obtain a total of 54 comments for that outlet, and a ninth Zeit article to counterbalance the added weight of the conservative tabloid TZ. In total, 42 news articles and 384 user comments were analysed.

\section{Coding}

To measure the diversity of viewpoints, in place of using sources cited as a proxy, our approach directly targets the interpretations articulated in the debate (Benson, 2009; Voakes et al., 1996). Thereby, we can distinguish different interpretations even if they originate from the same source. Our coding strategy reflects whether different frames construct similar or competing interpretations (Druckman, 2010; Herman, 1985). This enables us to assess diversity at the level of interpretative repertoires referred to by the constructed frames - distinct perspectives upon reality sustained by specific background assumptions about the nature of the world (Donati, 1992; Wetherell and Potter, 1988). To avoid a highly case-specific account, we introduce a deductive, theoretically grounded category system. Identifying distinct repertoires from recurrent patterns among these coded categories, we obtain a measure that allows a highly intersubjective, comparative assessment of viewpoint diversity (see also Matthes and Kohring, 2008).

Our coding procedure consisted of three consecutive steps. First, within each text, the main interpretative frame - providing the text's 'central organizing idea' (Gamson and Modigliani, 1987: 143) - was identified. For user comments, we considered one main frame, and up to two frames in journalistic articles. Where multiple frames were equally prominent, we selected those placed first.

Second, for each frame, the four frame elements defined by Entman (1993; problem definition, causal attribution, treatment recommendation, moral evaluation) were identified as far as present (see also Matthes and Kohring, 2008). Each frame was thus described by four propositions paraphrasing the main ideas of the four frame elements, using in vivo excerpts from the text. 
Table I. Logics of evaluation.

\begin{tabular}{|c|c|c|}
\hline Logic of evaluation & Good is... & Examples \\
\hline Inspired & $\begin{array}{l}\text {... what is true, divine, \& } \\
\text { amazing }\end{array}$ & $\begin{array}{l}\text { Righteous, pre-ordained, beautiful } \\
\text { False, uncreative, dull }\end{array}$ \\
\hline Popular & ...what the people want & $\begin{array}{l}\text { Preferred, popular, favourite } \\
\text { Resented, feared, isolated }\end{array}$ \\
\hline Moral & ...what is social, fair, \& moral & $\begin{array}{l}\text { Solidary, responsible, just } \\
\text { Inhumane, asocial, egoistic }\end{array}$ \\
\hline Civic & $\begin{array}{l}\text {...what is accepted, \& } \\
\text { conventional }\end{array}$ & $\begin{array}{l}\text { Legal, agreed, common } \\
\text { Scandalous, deviant, inappropriate }\end{array}$ \\
\hline Economic & $\begin{array}{l}\text {... what is profitable } \& \text { creates } \\
\text { value }\end{array}$ & $\begin{array}{l}\text { Beneficial, economic, affordable } \\
\text { Wasted, costly, unproductive }\end{array}$ \\
\hline Functional & ...what works & $\begin{array}{l}\text { Effective, necessary, quick } \\
\text { Dysfunctional, inefficient, useless }\end{array}$ \\
\hline Ecological & ...what is sustainable \& natural & $\begin{array}{l}\text { Sustainable, organic } \\
\text { Unnatural, irreversible }\end{array}$ \\
\hline
\end{tabular}

Third, we applied a differentiated category system. For each frame element, two kinds of codes were obtained: We first identified the main object of each problem definition, causal explanation, and treatment recommendation. Next, we coded the main logic of (inter)action by which this object constituted, caused, or acted upon the focal issue of the frame. For the moral evaluation, we coded the evaluative tendency, as well as the evaluative standard applied.

To categorize the evaluative standards applied, we followed Boltanski and Thévenot's (2006) argument that most evaluative judgments are based on a limited set of seven distinct evaluative logics (see also Thévenot et al., 2000): In their view, objects can be evaluated as 'good' or 'bad' because they are (or aren't) 'inspired', 'popular', 'moral', 'conventional', 'profitable', 'functional', or 'ecologically sustainable' (see Table 1). Concrete evaluations can be subsumed under one of these seven logics based on the ultimate kind of goal pursued by the respective evaluative standard: For instance, an evaluation as 'injust' refers to an ideal of harmonic social cohabitation, and thus to a moral logic.

To identify the primary kind of interaction connecting the objects of the frame's problem definition, causal explanation, and treatment recommendation, we further extrapolated the same logic beyond evaluative standards: We distinguish seven distinct logics of action, which correspond logically to the evaluative standards. For instance, inspired evaluations presume an action of believing or knowing, while economic evaluations only make sense if there are interactions of exchange and production in the world. The seven Logics of Action listed in Table 2 describe distinct modes of (inter)actions between people, things, ideas, and the world, which again subsume a wide diversity of concrete acts and relations.

Regarding the objects of a frame element, finally, we first distinguished whether the primary focus was on actors/agency or structure (Giddens, 1984). For actors, we differentiated whether collective or individual actors were in focus, and whether actors were 
Table 2. Logics of action.

\begin{tabular}{lll}
\hline Logic of action & Interactions between... & Examples \\
\hline Believing & $\ldots$ the mind \& the world & $\begin{array}{l}\text { Know, believe, trust, expect, invent, } \\
\text { imagine }\end{array}$ \\
Desire & $\ldots$ the mind \& objects & $\begin{array}{l}\text { Desire, support, resent, fear, pursue } \\
\text { Require to do, judge, admonish }\end{array}$ \\
Ought & $\ldots$ the mind \& people & $\begin{array}{l}\text { Advocate, regulate, concede, agree, fight } \\
\text { Negotiation }\end{array}$ \\
Exchange & $\ldots$ people \& the social world & Purchase, borrow, produce, consume \\
Technology & $\ldots$...objects \& the world & Function, collapse, cause \\
Life & $\ldots$ people \& the natural world & Regenerate, survive, harvest, pollute \\
\hline
\end{tabular}

represented as particular (emphasis on the difference compared with other actors) or common actors (emphasis on the similarity towards other actors). For structures, we differentiated whether structures were presented as descriptive of a given (or desired) status quo, or as deliberately created as prescriptive structures to achieve specific ends. Also, we again coded whether structures were presented as common (emphasis on the normality, universality or similarity to structures elsewhere) or particular (emphasis on difference and extraordinariness). For both actors and structures, we coded which social domain they belonged to, distinguishing between economic, political, academic, media and other actors, and economic, political, knowledge, social and other structures.

Based on this category system, each frame is characterized by (up to) three logics of action applied to three main objects cast in the roles of focal issue, cause and treatment, as well as the evaluative logic and tendency (see Figure 1). For each category, we retained the in vivo description alongside the applied code. In addition, we coded whether any references to each of the seven evaluative and seven action logics were present at all in the text, regardless of their use in one of the frame elements. Other content unrelated to the coded main frames was ignored.

The authors coded the coverage consensually, refining the coding instructions to achieve maximum transparency. The comments were coded by a research assistant after intensive training, achieving satisfactory intra-coder reliability given the complex coding procedure $(M($ Holsti $)=0.78, S D=0.10$, range: 1.0 (Ecological Logic present $)$ to 0.60 (Problem Definition's Object)). Only one variable (Problem Definition's Logic of Action, Holsti $=0.56$ ) failed to reach the 0.6 threshold.

\section{Results}

\section{Description: News' logics and frame devices}

In our presentation of results, we proceed from the analysis of news frames, over the user frames, to the comparative analysis. As Table 3 shows, most journalistic accounts focus on structures as the key problem $(n=33,78.6 \%)$ : Almost half the raised problem definitions concern prescriptive political structures (political strategies, policies, conflicts, etc.; $n=20,47.6 \%)$, as well as economic structures $(n=13,31.0 \%)$. Main concerns include the negotiations over 'help'/'bailout' packages, European fiscal legislation and 

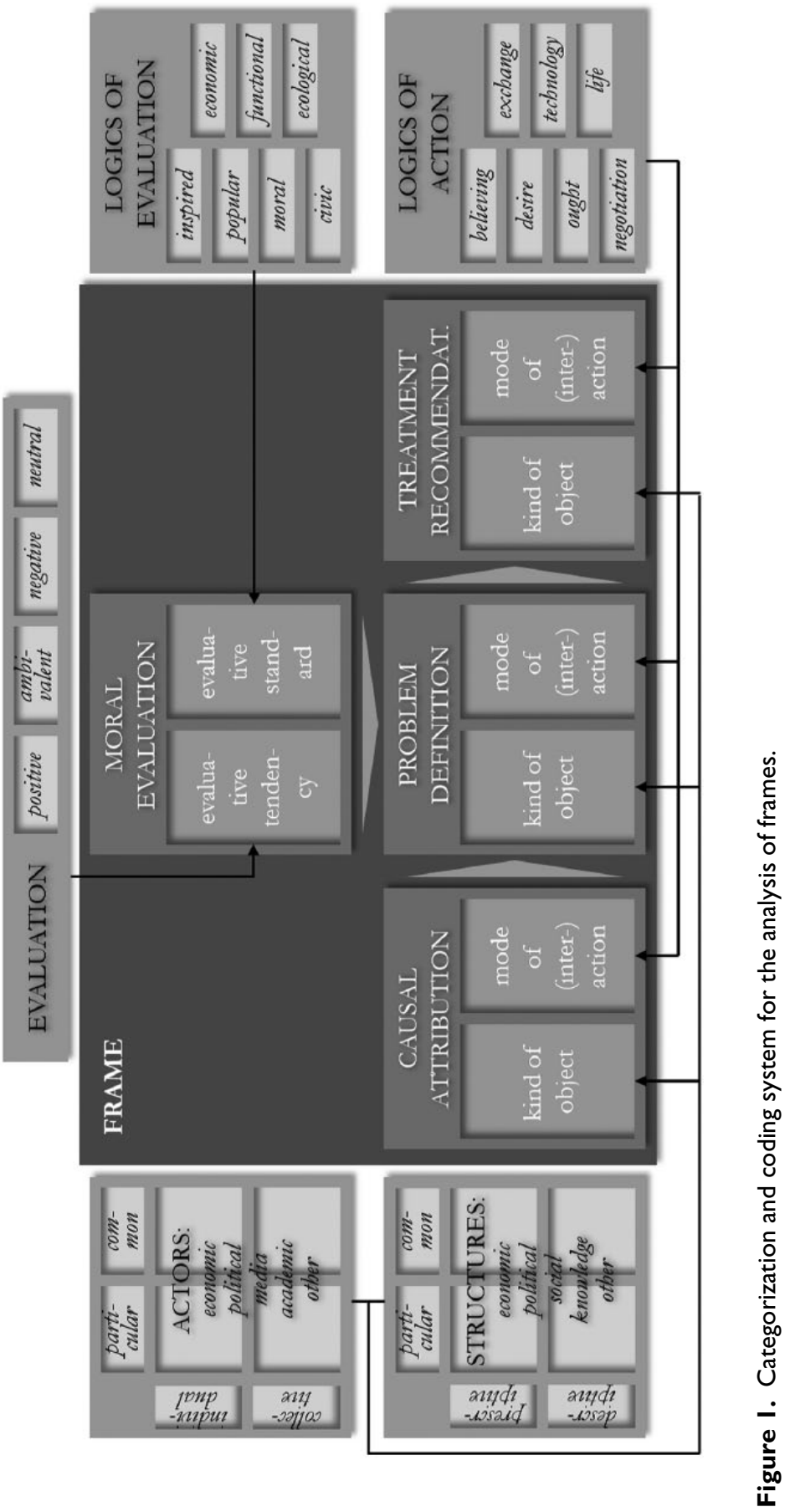
Table 3. Objects framed as problem definitions, causes or treatments in the news.

\begin{tabular}{|c|c|c|c|c|c|c|c|}
\hline & & $\begin{array}{l}\text { Problem } \\
\text { definition }\end{array}$ & $\begin{array}{l}\text { Causal } \\
\text { explanation }\end{array}$ & $\begin{array}{l}\text { Treatment } \\
\text { recomm. }\end{array}$ & $\begin{array}{l}\text { Problem } \\
\text { definition }\end{array}$ & $\begin{array}{l}\text { Causal } \\
\text { explanation }\end{array}$ & $\begin{array}{l}\text { Treatment } \\
\text { recomm. }\end{array}$ \\
\hline \multicolumn{2}{|c|}{ Actors } & \multicolumn{3}{|c|}{ Single/selected actors } & \multicolumn{3}{|c|}{ Most/all actors } \\
\hline \multirow{5}{*}{ 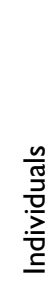 } & Political & $3(7.1 \%)$ & I (2.4\%) & I (2.4\%) & $2(4.8 \%)$ & - & - \\
\hline & Economic & - & - & I (2.4\%) & - & - & - \\
\hline & Academic & - & - & - & - & - & - \\
\hline & Media & - & - & - & - & - & - \\
\hline & Other & - & - & - & - & - & - \\
\hline \multirow{5}{*}{ 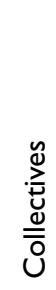 } & Political & I (2.4\%) & 5 (11.9\%) & 19 (45.2\%) & - & - & - \\
\hline & Economic & $3(7.1 \%)$ & 3 (7.l\%) & $3(7.1 \%)$ & - & - & - \\
\hline & Academic & - & - & - & - & - & - \\
\hline & Media & - & - & - & - & - & - \\
\hline & Other & - & - & - & - & - & - \\
\hline \multicolumn{2}{|c|}{ Structures } & \multicolumn{3}{|c|}{ Specific structures } & \multicolumn{3}{|c|}{ General structures } \\
\hline \multirow{5}{*}{ 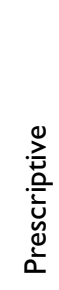 } & Political & $12(28.6 \%)$ & $2(4.8 \%)$ & I (2.4\%) & $8(19.0 \%)$ & I (2.4\%) & 2 (4.8\%) \\
\hline & Economic & $8(19.0 \%)$ & - & 2 (4.8\%) & - & - & I (2.4\%) \\
\hline & Beliefs & - & - & - & - & - & - \\
\hline & Social & - & - & - & - & - & - \\
\hline & Other & - & - & - & - & - & - \\
\hline \multirow{7}{*}{ 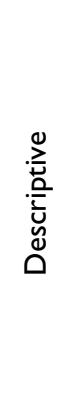 } & Political & - & 2 (4.8\%) & - & - & I (2.4\%) & - \\
\hline & Economic & 5 (11.9\%) & II (22.2\%) & I (2.4\%) & - & 3 (7.1\%) & 2 (4.8\%) \\
\hline & Beliefs & - & - & - & - & I (2.4\%) & - \\
\hline & Social & - & - & I (2.4\%) & - & - & - \\
\hline & Other & - & - & - & - & - & - \\
\hline & & $0(0.0 \%)$ & $12(28.6 \%)$ & 8 (19.0\%) & \multicolumn{3}{|l|}{ No object } \\
\hline & & 42 & & & \multicolumn{3}{|l|}{ N Articles } \\
\hline
\end{tabular}

treaties and specific economic strategies (debt relief, etc.). Some articles discuss economic realities ( $n=5,11.9 \%$; e.g. budget deficits), and only few focus on political (notably, Merkel, the German government, EU states; $n=6,14.2 \%$ ) and economic actors (usually banks; $n=3,7.1 \%$ ). Also, most identified causes were structural, albeit with 
much more emphasis on economic, descriptive structures $(n=14,33.4 \%$ : debts, real estate crises, economic performance, etc.). Political causes were identified both in political conflicts ( $n=6,14.2 \%)$ and (usually collective) actors $(n=6,14.2 \%$, typically governments). Almost one-third of articles did not attribute responsibility at all $(n=12$, $28.6 \%$ ). Concerning recommended treatments, journalists predominantly hold political collective actors - the German, Greek and Spanish governments, the EU - responsible for devising suitable actions $(n=19,45.2 \%)$. Other addressees for solving the identified problems concern individual political and economic collective actors (e.g. the German minister of finance, creditors). Structural solutions are sought by advocating (mostly economic) measures $(n=6,14.3 \%)$ and, less frequently, pointing at (mostly economic) situations $(n=4,9.5 \%)$. Eight articles $(19.0 \%)$ refrained from giving any treatment recommendation. The general tendency in the news, hence, is to blame political problems on economic situations, and point at collective political actors for solutions.

Looking at recurrent patterns in the news coverage, 12 relevant frame fragments (total explained variance $(E V): 58.7 \%$, eigenvalues $(e)$ above 2 ) could be identified using exploratory factor analysis: One fragment labelled 'Negotiate solutions' groups treatment recommendations addressed at specific collective political actors, who must negotiate better solutions $(e=3.0, E V: 6.0 \%$, loadings $(\lambda)=.55$ to .89$)$. 'Regulated capitalism' groups specific economic actions and collective actors considered problematic, which can be redressed by specific policies ( $e=2.9, E V: 5.9 \%, \lambda=.33$ to .88). 'Selfish agendas' comprises problematic desires of collective actors, which are caused by specific political structures and negotiations ( $e=2.8, E V: 5.6 \%, \lambda=.34$ to .79). According to 'Market failures', specific economic situations and actions cause various problems, which require political treatment, but are evaluated functionally ( $e=2.7, E V: 5.4 \%, \lambda=.31$ to .72$)$. 'Counteract painful measures' describes specific individual actors suffer as the consequence of particular policies and other prescriptive structures, which must be changed by other such structures, and evaluated conventionally $(e=2.6, E V: 5.1 \%, \lambda=.34$ to .87$)$. 'Change our ways of life' holds problems caused by specific desires, which require social changes in the existing structures of life $(e=2.4, E V: 4.7 \%, \lambda=.59$ to .91$)$. 'False economics doctrines' groups problems rooted in our understanding of the current economic situation, which is caused by economic mechanics but must be evaluated morally $(e=2.3$, $E V: 4.7 \%, \lambda=.31$ to .76 ). According to the 'Complex world', our insufficient grasp of the overall situation is the cause of current specific situations, and what helps is changing the overall situation ( $e=2.3, E V: 4.6 \%, \lambda=.33$ to .84 ). 'Understand crisis mechanisms' sees technical causes behind various problems that require a better knowledge of the world, in a morally evaluated sense ( $e=2.3, E V: 4.5 \%, \lambda=.60$ to .69). In 'Politics vs. economy', political problems of specific collective actors and common measures $(e=2.1, E V: 4.2$, $\lambda=.38$ to .47$)$ are contrasted against specific problematic economic measures that are evaluated economically $(\lambda=-.41$ to .84$)$. 'What the people want' focuses on common individuals' desires ( $e=2.0, E V: 4.0 \%, \lambda=.45$ to .83$)$, which are evaluated by popularity. 'Decadence', finally, is a fragment that understands specific individuals' ways of living as causes of relevant problems ( $e=2.0, E V: 4.0 \%, \lambda=.87$ to .90$)$.

Looking at the evaluative and action logics referenced in the news, we first find that a political $(95 \%)$, technical $(88 \%)$ and economic logic $(86 \%)$ is present in almost all articles (Figure 2). However, the logics contribute differently to the news framing: The 


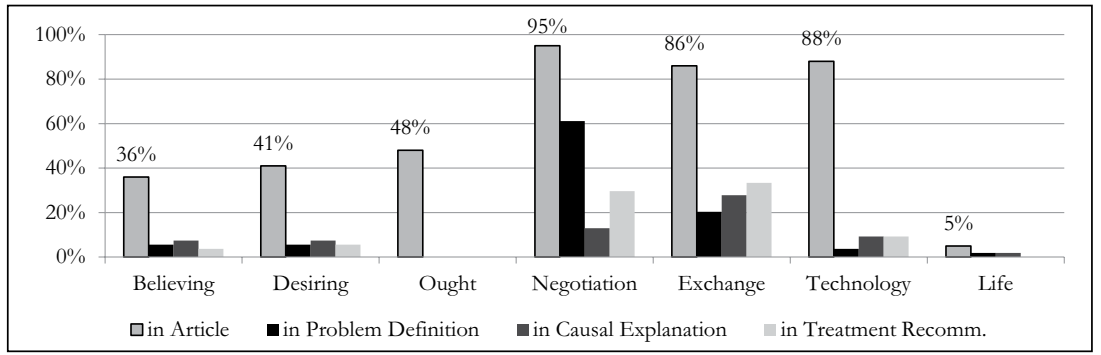

Figure 2. Shares of news articles mentioning each logic of action.

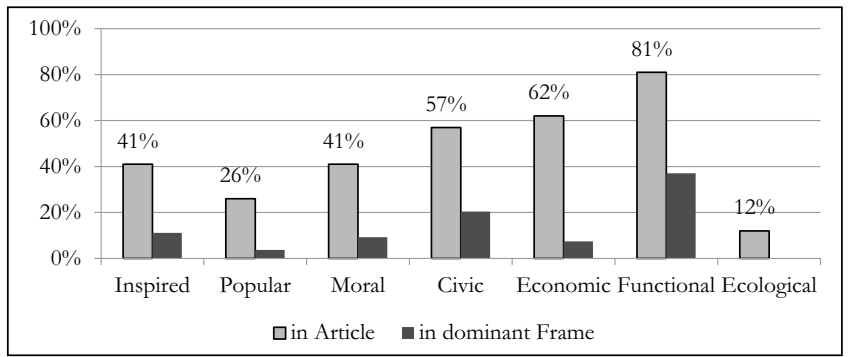

Figure 3. Shares of news articles mentioning each logic of evaluation.

dominant role of negotiations is underlined by their high salience in frames' problem definitions. Exchange logics dominate most causal accounts, while both exchange and negotiation play important roles in the recommended treatments. Despite its frequent presence in the articles coded, the technological logic of action plays only a subordinate role in the articles' main frames. Regarding the evaluative logics raised, Figure 3 shows that functional evaluations dominate before economic and civic ones. This dominance is underlined by the evaluative logics raised by the main news frames, where twice as many evaluate functionally (37\%) compared with the second, civic logic (20\%). Other evaluative standards are still referenced, but the depoliticized, technocratic holds the centre stage. The tone of the coverage is split evenly into $12(28.6 \%)$ positive, $16(38.1 \%)$ negative and 14 neutral or ambivalent articles (33.3\%).

Searching for specific patterns of evaluative and action logics, a factor analysis identifies six perspectives that could be understood as interpretative repertoires ( $E V: 69 \%)$ : The first, namely, 'Good Life Repertoire (R.)', comprises the logic of life alongside moral and ecological evaluations ( $e=1.9, E V: 13.3 \%, \lambda=.62$ to .66$)-$ a factor that is highly distinct, but covers very few actual references in the coded articles. An 'Understanding the Crisis R.' is led by inspired judgments and the logic of believing, and further refers to a technical logic and civic evaluations $(e=1.9, E V: 13.2 \%, \lambda=.46$ to $.85)$; it formulates a need for an appropriate understanding of the crisis to inform common policy. A 'Crisis Mechanics R.' focuses on economic mechanics, wherein exchange and technical actions are evaluated economically ( $e=1.7, E V: 12.3 \%, \lambda=.63$ to .78$)$, 
contributing to a macro-economic point of view. The ' (Ir)rational Expectations R.' applies functional evaluations to actions of believing and ought $(e=1.5, E V: 10.5 \%$, $\lambda=.45$ to .80 ), reflecting the critique of allegedly irrational demands and ideas. A 'Political Solutions R.' groups desires and negotiations with moral and civic evaluations into a political negotiation-of-interests repertoire $(e=1.4, E V: 10.3 \%, \lambda=.34$ to .80$)$. Finally, the 'Wishlists vs. Requirements R.' contrasts popularity and desire ( $e=1.4, E V$ : $9.8, \lambda=.57$ to .79$)$ against functional evaluations $(\lambda=-.51)$, reflecting the polarity of frames between technocratic accounts and reflections of the desirable.

\section{Description: Users' logics and frame devices}

The objects of news users' frame constructions deviate markedly from those presented in the news (Table 4). News users generally emphasize actors rather than structures: 138 out of 384 comments $(35.9 \%)$ define specific individual $(60,15.6 \%)$ or collective actors $(78,20.3 \%)$ as the key concern, and another 78 (20.4\%) focus on common individual $(51,13.5 \%)$ or collective $(27,7.0 \%)$ actors. The overwhelming emphasis is on political actors $(150,39.1 \%)$, out of which 104 cases $(27.1 \%)$ refer to specific political actors. Economic actors $(35,9.1 \%)$ still play some role, while other actor types are again largely ignored. If comments discuss structural problems, these are either economic $(50,13.0 \%$, then usually specific) or political $(47,12.2 \%$, then usually general). Fifty comments $(13.0 \%)$ do not provide a discernable problem definition. Also for attributing causal responsibility, users prefer political actors $(72,18.8 \%$, mostly specific ones), or actors in general $(102,26.6 \%)$. With the exception of economic realities $(19,4.9 \%)$, structural causes are largely irrelevant. Every second user commentary $(176,45.8 \%)$ does not attribute responsibility. Similarly, only 126 comments $(32.8 \%)$ mention explicit solutions: Again, political actors feature most prominently $(59,15.4 \%)$, either as specific actors, or as 'the politicians' in general $(19,4.9 \%)$. However, a relevant share of comments also addresses 'other' individuals $(23,6.0 \%)$ or the media $(5,1.3 \%)$. User comments thus focus on the actions of political individuals and organizations, and mobilize more individuals and actors (or simply 'the people') to explain and redress them.

Searching for recurrent patterns, 10 relevant frame fragments are identified ( $E V$ : 28.0\%): A fragment 'Bad economic situation' focuses on economic problems of economic objects, which are not evaluated against a civic logic $(e=2.2, E V: 3.3 \%, \lambda=.31$ to .80$)$. 'Knowledge-based crisis policy' concerns problems caused by lacking knowledge and addressed through specific functional measures evaluated politically $(e=2.0$, $E V: 2.9 \%, \lambda=.34$ to .76$)$. 'Collective policy formation' emphasizes political collective actors' negotiations as treatments $(e=1.9, E V: 2.9 \%, \lambda=.60$ to .83$)$, while 'Collective policy causes' sees political collective actors' negotiations as causes $(e=1.9, E V: 2.8 \%$, $\lambda=.64$ to .81). 'Other kinds of causes' focuses on specific problematic situations somewhat unrelated to the captured dimensions (coded 'other' as problem and cause; $e=1.8$, $E V: 2.7 \%, \lambda=.32$ to .77$)$. 'Ignorant politicians' deals with personal beliefs of political individual actors as causes and problems $(e=1.8, E V: 2.7 \%, \lambda=.37$ to .82$)$. 'Change your way of life' raises demands for individual behaviour as solution ( $e=1.8, E V: 2.7 \%$, $\lambda=.37$ to .73). 'Politicians' tasks' expresses that 'the politicians' ought to do something ( $e=1.8, E V: 2.7 \%, \lambda=.45$ to .83 ). 'Flawed economic system' focuses on specific flaws 
Table 4. Objects framed as problem definitions, causes or treatments in user commentary.

\begin{tabular}{|c|c|c|c|c|c|c|c|}
\hline & & $\begin{array}{l}\text { Problem } \\
\text { definition }\end{array}$ & $\begin{array}{l}\text { Causal } \\
\text { explanat. }\end{array}$ & $\begin{array}{l}\text { Treatment } \\
\text { recomm. }\end{array}$ & $\begin{array}{l}\text { Problem } \\
\text { definition }\end{array}$ & $\begin{array}{l}\text { Causal } \\
\text { explanat. }\end{array}$ & $\begin{array}{l}\text { Treatment } \\
\text { recomm. }\end{array}$ \\
\hline Acto & & Single/select & actors & & Most/all acto & & \\
\hline & Political & 45 (II.7\%) & 20 (5.2\%) & 14 (3.6\%) & 33 (8.6\%) & II (3.I\%) & 19 (4.9\%) \\
\hline & Economic & $2(0.5 \%)$ & $2(0.5 \%)$ & I $(0.3 \%)$ & $10(2.6 \%)$ & $5(1.3 \%)$ & - \\
\hline$\underline{w}$ & Academic & - & I $(0.3 \%)$ & - & - & - & - \\
\hline$\frac{3}{7}$ & Media & $2(0.5 \%)$ & - & - & - & - & I $(0.3 \%)$ \\
\hline$\underline{\underline{S}}$ & Other & II (3.I\%) & $4(1.0 \%)$ & $12(3.1 \%)$ & $8(2.1 \%)$ & $2(0.5 \%)$ & II (3.1\%) \\
\hline & Political & 59 (15.4\%) & 36 (9.4\%) & 22 (5.7\%) & I3 (3.4\%) & $5(1.3 \%)$ & $4(1.0 \%)$ \\
\hline & Economic & 13 (3.4\%) & 7 (1.8\%) & $7(1.8 \%)$ & $10(2.6 \%)$ & $7(1.8 \%)$ & $5(1.3 \%)$ \\
\hline$\tilde{y}$ & Academic & - & - & - & - & - & - \\
\hline$\underline{\bar{U}}$ & Media & $3(0.8 \%)$ & I $(0.3 \%)$ & $4(1.0 \%)$ & $2(0.5 \%)$ & I $(0.3 \%)$ & - \\
\hline U & Other & $3(0.8 \%)$ & - & - & $2(0.5 \%)$ & - & - \\
\hline Stru & tures & Specific stru & ures & & General stru & Ires & \\
\hline & Political & $9(2.3 \%)$ & $2(0.5 \%)$ & $5(1.3 \%)$ & $23(6.0 \%)$ & $7(1.8 \%)$ & $3(0.8 \%)$ \\
\hline & Economic & $19(4.9 \%)$ & $9(2.3 \%)$ & $3(0.8 \%)$ & $2(0.5 \%)$ & - & - \\
\hline$\stackrel{\Perp}{\geq}$ & Beliefs & $2(0.5 \%)$ & - & I $(0.3 \%)$ & - & - & I $(0.3 \%)$ \\
\hline 嵓 & Social & I $(0.3 \%)$ & - & - & - & - & - \\
\hline 2 & Other & $3(0.8 \%)$ & $4(1.0 \%)$ & $2(0.5 \%)$ & $2(0.5 \%)$ & - & - \\
\hline & Political & $5(1.3 \%)$ & $3(0.8 \%)$ & I $(0.3 \%)$ & $10(2.6 \%)$ & $3(0.8 \%)$ & $2(0.5 \%)$ \\
\hline & Economic & 16 (4.2\%) & $9(2.3 \%)$ & - & 13 (3.4\%) & $10(2.6 \%)$ & $6(1.6 \%)$ \\
\hline & Beliefs & $5(1.3 \%)$ & I $(0.3 \%)$ & - & I $(0.3 \%)$ & - & - \\
\hline 产 & Social & - & - & - & $3(0.8 \%)$ & - & - \\
\hline ڤั & Other & $2(0.5 \%)$ & $6(1.6 \%)$ & I (0.3\%) & $2(0.5 \%)$ & $2(0.5 \%)$ & I $(0.3 \%)$ \\
\hline & & 50 (13.0\%) & 176 (45.8\%) & I 26 (32.8\%) & No Object & & \\
\hline & & 384 & & & $\mathrm{~N}$ comments & & \\
\hline
\end{tabular}

in economic reality as cause $(e=1.8, E V: 2.7 \%, \lambda=.32$ to .79$)$. 'Change public economics' asks the economies of Europe to adjust their economic behaviour ( $e=1.8, E V: 2.7 \%$, $\lambda=.54$ to .76). However, these 10 fragments only account for $28.0 \%$ of the variance in the data, reflecting considerable diversity in the commentary analysed.

Assessing the logics of action referenced in user commentary, we find that the distribution is much more even than in the news. Although the comments mention fewer 


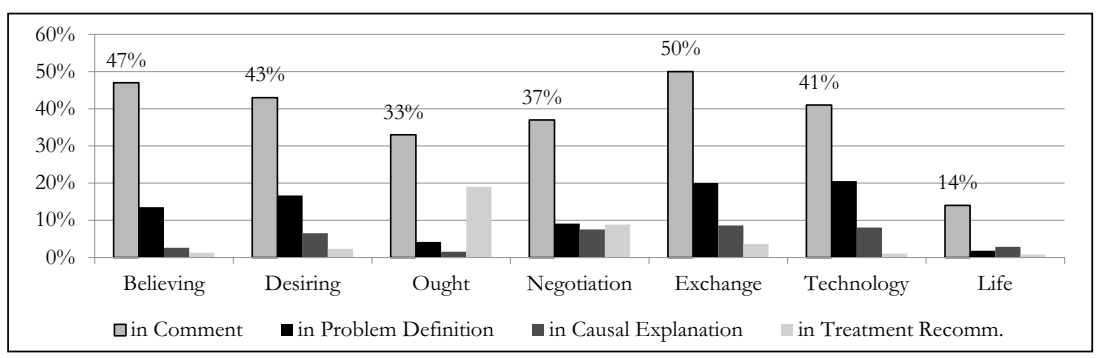

Figure 4. Shares of user comments mentioning each logic of action.

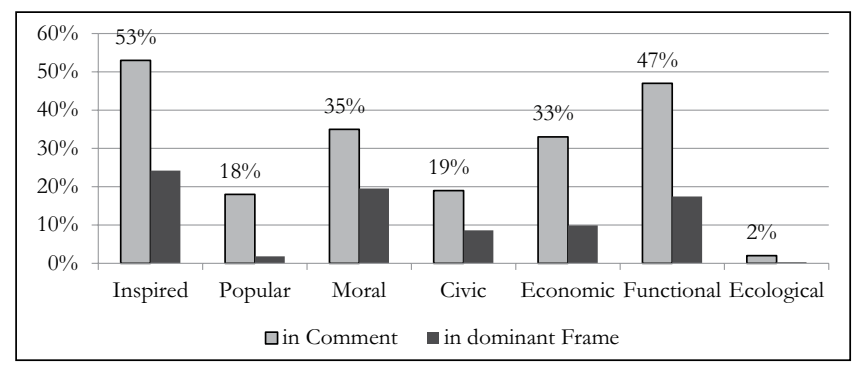

Figure 5. Shares of user comments mentioning each logic of evaluation.

logics in total, all logics except for life appear in every second to third comment. Their roles differ again: While discussed problems and causes most commonly concern the functioning $(21 \%, 8 \%)$ and economics $(20 \%, 9 \%)$ of the crisis, the dominant solution strategy focuses on ought (19\%) and negotiation (9\%). Regarding evaluative logics, inspired and functional logics dominate most user comments, reflecting a widespread recognition of rather a-political views upon the crisis. However, in the frames constructed by news users, moral evaluations $(20 \%)$ play an important role behind inspired ones $(24 \%)$, while the functional evaluations are more referenced than actually endorsed (17\%). Civic evaluations play only a minor role (9\%). Most evaluations in commentary are clearly negative $(n=262,68.4 \%)$, some are ambivalent $(n=70,18.3 \%)$ and only very few are positive $(n=39,10.2 \%)$ or neutral $(n=12,3.1 \%)$ (see Figures 4 and 5$)$.

Assessing the patterns by which these logics are referenced, similar repertoires emerge compared with those found in the news ( $E V: 54 \%$ ): An 'Economic Mechanics R.' evaluates economic exchanges by economic standards $(e=1.6, E V: 11.4 \%, \lambda=.84$ to .86). The 'Political Solutions R.' contains the familiar group of demands and negotiations and their popular and political evaluations ( $e=1.6, E V: 11.2 \%, \lambda=.39$ to .71$)$. An 'Understanding the Crisis R.' contains a functional-beliefs repertoire of believing, technical interactions and functional as well as inspired evaluations, amended by a reference to negotiations ( $e=1.5, E V: 11.1 \%, \lambda=.36$ to .62 ). The '(In)appropriate Demands R.' subjects popular demands and oughts to moral and functional evaluation $(e=1.5, E V$ : $10.8 \%, \lambda=.40$ to .73 ). Finally, the 'Good Life R.' contains the sustenance-perspective 
Table 5. Similarity of frame fragments found in the news and user commentary.

\begin{tabular}{|c|c|c|c|c|}
\hline \multicolumn{2}{|c|}{ Frame fragments in the news } & \multirow[t]{2}{*}{ Similarity } & \multicolumn{2}{|c|}{$\begin{array}{l}\text { Frame fragments in user } \\
\text { commentary }\end{array}$} \\
\hline No. & Name & & No. & Name \\
\hline 1 & negotiate solutions & $\begin{array}{l}\text { high } \\
\text { medium }\end{array}$ & $\begin{array}{l}3 \\
8\end{array}$ & $\begin{array}{l}\text { collective policy formation } \\
\text { politicians' tasks }\end{array}$ \\
\hline 2 & regulated capitalism & medium & 1 & bad economic situation \\
\hline 3 & selfish agendas & medium & 4 & collective policy causes \\
\hline 4 & market failures & medium & 9 & flawed economic system \\
\hline 5 & counteract painful measures & & & \\
\hline 6 & change our ways of life & high & 7 & change your way of life \\
\hline 7 & false economics doctrines & medium & 10 & change public economics \\
\hline 8 & complex world & medium & 6 & ignorant politicians \\
\hline 9 & understand crisis mechanisms & medium & 2 & knowledge-based crisis policy \\
\hline 10 & politics vs. economy & & & \\
\hline II & what the people want & & & \\
\hline \multirow[t]{2}{*}{12} & Decadence & & & \\
\hline & & & 5 & other kinds of causes \\
\hline
\end{tabular}

capturing the few references to the logics of life and ecology, evaluated also by inspired standards $(e=1.4, E V: 9.7 \%, \lambda=.44$ to .73$)$.

\section{Comparative analysis}

Comparing journalistic accounts and user comments, users focus much more on agency than on structure: While actors dominate only the recommended solutions in the news, users focus on actors (often generalized such as 'the people', 'the politicians') also as problems and causes. Journalists emphasize specific prescriptive structures (policies, exchanges, measures) as problems, and refer to current circumstances (descriptive structures) as causes for discussed issues. Users generally ignore the media's emphasis on political negotiations, economic exchanges, and the mechanisms of the crisis. In their comments, all kinds of actions are referenced in similar measure. In the case of evaluative logics, users' views differ even more from the news. Not only do users level the news' heavy bias towards functional evaluations, but they even refer most saliently to a different, inspired logic of evaluation. Users evaluate issues in the crisis mostly as right/ wrong and good/bad, while the media use mostly functional, economic, and conventional evaluations.

However, many of the frame fragments found in the news come back in user commentary (Table 5): Of the six repertoires detected in the news, three (Good Life, Understanding the Crisis, Political Solutions) appear nearly unchanged in user commentary, and two more are only subtly altered (Economic Mechanics omitting the functional necessity of Crisis Mechanics, and the (In)appropriate Demands focussing more on desire than belief compared with (Ir)rational Expectations). Either user commentary 
merely echoes the perspectives taken in the news, manipulating the relative salience of components but contributing little to diversity or users systematically complement fragments and perspectives learned from news coverage elsewhere to complement a given article, increasing the diversity of views on a specific news platform, even if not of news discourse at large. Regression analysis supports both interpretations: When the news article focussed on economic exchanges, user commentary tends to do the same $(\beta=.17$, $p<.01)$ - Possibly, users lack the confidence and knowledge to augment the rather technical economic news. Civic evaluations in the news predict moral evaluations in commentary $(\beta=.16, p<.01)$, and vice versa $(\beta=.14, p<.05)$ - User comments were also significantly more likely to focus on acts of desiring if the news had included a moral evaluation $(\beta=.16, p<.05)$, and no functional evaluation $(\beta=-.19, p<.01)$. Similarly, news articles evaluating morally $(\beta=.14, p<.05)$ and civically $(\beta=.17, p<.01)$ increase the amount of references to negotiations in user commentary. News evaluating morally $(\beta=.22, p<.01)$ and not in a logic of inspiration $(\beta=-15, p<.05)$ are followed by popular evaluation logics in user commentary: Users thus systematically complemented related logics to construct a more complete notion of political preference formation processes. The same can also happen for mechanistic-ecological accounts: Technical action in user commentary was predicted by acts of believing $(\beta=.13, p<.05)$ in the news and the absence of moral evaluations $(\beta=-.17, p<.05)$. The former also predicts functional evaluations in user comments $(\beta=.20, p<.001)$, while the latter $(\beta=-.14$, $p<.05)$, technical $(\beta=.14, p<.05)$ and life actions in the media $(\beta=.19, p<.01)$ predict commentary on the logic of life.

\section{Discussion}

The above results illuminate several key mechanisms shaping both news journalism and user commentary in the financial crisis: Journalistic representations focus on only few main repertoires; the voice of economic experts and financial institutions is reflected in the high salience of economic interdependencies in the debate; the intergovernmental mode of decision making contributes the bulk of references to political activity; and both repertoires contribute to the salience of depoliticized technocracy (Althaus et al., 1996; Bennett, 1996; Hobolt, 2009). The functional perspective primarily provides the evaluative context, while the news cast policy actors in a central, active role. Consequently, several articles arrive at positive evaluations of political actions: Problems originate outside their responsibility, but government has moved to address the problem (Iyengar, 1991). Alternative perspectives are referenced, but remain outside the dominant frame (Dardis, 2009). Crisis measures are depoliticized and judged by their legality and effectiveness (Herman and Chomsky, 1988; Hilgartner, 2000).

By contrast, user commentary focuses more on political actors, but less on political action. Users freely discuss politicians' faulty ideas, misguided demands and economic policies. Likewise, they include problems outside political decision making in their frames (e.g. flaws in contemporary capitalism, the needs and behaviour of the people). Users evaluate more diversely and politically, invoking moral and inspired logics alongside functional ones (Boltanski and Thévenot, 2006), and targeting also banks and bankers, the media, and the people themselves (Iyengar, 1991). Doubtlessly, many user frames 
misrepresent the collective, institutionalized and incremental formation of crisis policies, and evidence-based contributions were rare (Graham, 2009). However, the relative freedom with which users pillaged news frame constructions to construct their own views documents their considerable independence from hegemonic news discourse (Druckman, 2004). At the same time, the findings also document limits of this independence: Users rarely construct novel interpretative repertoires outside the news discourse (Gamson, 1992). They complement news information using popular wisdom and historical analogies, but rarely bring in genuinely different information. Finally, users have little constructive to say about possible solutions or treatments. The user debate remains, in most parts, reactive and critical.

\section{Limitations}

The findings presented here may not transfer to other countries and moments during the crisis as we focussed on few news events in only one, somewhat exceptional country within the financial crisis. Furthermore, the content-analytic strategy introduced presents an abstraction from the manifest content that sacrifices considerable nuance to obtain an overall measure of diversity in repertoires and frames. This strategy is devised to apply to news debates on variable issues, enabling a comparative analysis of diversity. While for each specific case, a frame codebook tailored to the situation may provide superior detail, we believe that a generic, transferable strategy has a legitimate place in the methodological tool box.

\section{Conclusion}

This study demonstrates that user commentary is constrained by hegemonic news discourse, but able to contribute valuably to diversity nevertheless. Changing perspectives on agency, politicizing evaluations and mobilizing the rich interpretative resources of popular wisdom, commentators complement dominant news repertoires. This finding underlines the need for a more detailed, content-focussed research agenda to assess news diversity beyond the indexing of few official standpoints and competing dominant frames. Introducing a methodology for comparatively analysing the diversity of interpretations, we argue that such research is not merely desirable, but also practically feasible. Through the systematic assessment of the selectiveness and viewpoint diversity across different public, we can gain a much more nuanced appraisal of the performance and failures of journalistic reporting, especially in crises and conflicts.

\section{Funding}

This research received no specific grant from any funding agency in the public, commercial or not-for-profit sectors.

\section{References}

Althaus SL, Edy JA, Entman RM, et al. (1996) Revising the indexing hypothesis: Officials, media, and the Libya Crisis. Political Communication 13: 407-421. 
Andrews KT and Caren N (2010) Making the news: Movement organizations, media attention, and the public agenda. American Sociological Review 75: 841-866.

Baden C (2010) Communication, Contextualization, \& Cognition: Patterns \& Processes of Frames' Influence on People's Interpretations of the EU Constitution. Delft: Eburon.

Baumgartner FR, De Boef S and Boydstun AE (2008) The Decline of the Death Penalty and the Discovery of Innocence. Cambridge: Cambridge University Press.

Benford RD (1993) Frame disputes within the nuclear disarmament movement. Social Forces 71(3): 677-701.

Bennett WL (1996) An introduction to journalism norms and representations of politics. Political Communication 13: 373-384.

Benson R (2009) What makes news more multiperspectival? A field analysis. Poetics 37: 402-418.

Benson R and Hallin DC (2007) How states, markets, and globalization shape the news: The French and US national press, 1965-97. European Journal of Communication 22(1): 27-48.

Böcking T(2009)Strategisches Framing: Gesellschaftliche AkteureundihreEinflussnahmeversuche auf die mediale Debatte über die embryonale Stammzellenforschung in Deutschland [Strategic Framing: Societal Actors and their Attempts at Influencing the Media Debate About Embryonic Stem Cell Research in Germany]. Cologne: Halem.

Boltanski L and Thévenot L (2006) On Justification: Economies of Worth. Princeton, NJ: Princeton University Press.

Bowman S and Willis C (2003) We Media: How Audiences Are Shaping the Future of News and Information. Available at: http://www.hypergene.net/wemedia/download/we_media.pdf.

Bronstein C (2005) Representing the third wave: Mainstream print media framing of a new feminist movement. Journalism \& Mass Communication Quarterly 82(4): 783-803.

Bruns A (2005) Gatewatching: Collaborative Online News Production. New York: Peter Lang.

Bruns A, Burgess JE, Crawford K, et al. (2012)\#qldfloods and@QPSMedia: Crisis Communication on Twitter in the 2011 South East Queensland Floods. Brisbane, QLD, Australia: QUT.

Carpenter S (2010) A study of content diversity in online citizen journalism and online newspaper articles. New Media \& Society 12(7): 1064-1084.

Chong D and Druckman JN (2007) Framing public opinion in competitive democracies. American Political Science Review 101(4): 637-655.

Dardis FE (2009) Marginalization devices in U.S. press coverage of Iraq war protest: A content analysis. Mass Communication and Society 9(2): 117-135.

De Vreese CH (2004) The effects of frames in political television news on issue interpretation and frame salience. Journalism \& Mass Communication Quarterly 81: 36-52.

Donati PR (1992) Political discourse analysis. In: Diani M and Eyerman R (eds) Studying Collective Action. London: SAGE pp. 136-167.

Druckman JN (2004) Political preference formation: Competition, deliberation, and the (ir)relevance of framing effects. American Political Science Review 98(4): 671-686.

Druckman JN (2010) Competing frames in a political campaign. In: Schaffner B and Sellers P (eds) Winning with Words: The Origins and Impact of Political Framing. New York: Routledge, pp. 101-120.

Entman RM (1993) Framing: Toward clarification of a fractured paradigm. Journal of Communication 43(4): 51-58.

Ferree MM, Gamson WA, Gerhards J and Rucht D (2002) Shaping Abortion Discourse: Democracy and the Public Sphere in Germany and the United States. New York: Cambridge University Press.

Galtung J and Ruge MH (1965) The structure of foreign news: The presentation of the Congo, Cuba and Cyprus Crisis in Four Norwegian Newspapers. Journal of Peace Research 2(1): 64-91. 
Gamson WA (1992) The social psychology of collective action. In: Morris AD and McClurg Mueller C (eds) Frontiers in Social Movement Theory. New Haven, CT: Yale University Press, pp. 53-76.

Gamson WA and Modigliani A (1987) The changing culture of affirmative action. In: Braungart RG and Braungart MM (eds) Research in Political Sociology, vol. 3. Greenwich, CT: JAI Press, pp. 137-177.

Gamson WA, Croteau D, Hoynes W, et al. (1992) Media images and the social construction of reality. Annual Review of Sociology 18: 373-393.

Gandy OH (1982) Beyond Agenda Setting: Information Subsidies and Public Policy. Norwood, NJ: Ablex Publishers.

Garrett RK (2009) Echo chambers online? Politically motivated selective exposure among Internet news users. Journal of Computer-Mediated Communication 14(2): 265-285.

Gerhards J and Schäfer MS (2010) Is the Internet a better public sphere? Comparing old and new media in the USA and Germany. New Media \& Society 12(1): 143-160.

Giddens A (1984) The Constitution of Society: Outline of the Theory of Structuration. Cambridge: Polity Press.

Graber DA (1988) Processing the News: How People Tame the Information Tide, 2nd edn. White Plains, NY: Longman.

Graham T (2009) What's Wife Swap Got to Do With It? Talking Politics in the Net-Based Public Sphere. Amsterdam: Amsterdam University Press.

Habermas J (1991) The Structural Transformation of the Public Sphere: An Inquiry into a Category of Bourgeois Society. Cambridge, MA: The MIT Press.

Hayes D and Guardino M (2010) Whose views made the news? Media coverage and the march to war in Iraq. Political Communication 27: 59-87.

Herman ES (1985) Diversity of news: 'Marginalizing' the opposition. Journal of Communication 35(3): $135-146$.

Herman ES and Chomsky N (1988) Manufacturing Consent: The Political Economy of the Mass Media. New York: Pantheon Books.

Hilgartner S (2000) Science on Stage: Expert Advice as Public Drama. Stanford, CA: Stanford University Press.

Hobolt SB (2009) Europe in Question: Referendums on European Integration. Oxford: Oxford University Press.

Hutchins B and Lester L (2006) Environmental protest and tap-dancing with the media in the information age. Media, Culture \& Society 28(3): 433-451.

Iyengar S (1991) Is Anyone Responsible? How Television Frames Political Issues. Chicago, IL: The University of Chicago Press.

Iyengar S and Simon A (1993) News coverage of the GulfCrisis and public opinion. Communication Research 20(3): 365-383.

Matthes J and Kohring M (2008) The content analysis of media frames: Toward improving reliability and validity. Journal of Communication 58: 258-279.

Motta G and Baden C (2013) Evolutionary factor analysis of the dynamics of frames: Introducing a method for analyzing high-dimensional semantic data with time-changing structure. Communication Methods and Measures 7(1): 48-84.

Neuman WR, Just MR and Crigler AN (1992) Common Knowledge: News and the Construction of Political Meaning. Chicago, IL: The University of Chicago Press.

Reese SD (2010) Finding frames in a web of culture: The case of the war on terror. In: D'Angelo P and Kuypers JA (eds) Doing News Framing Analysis: Empirical and Theoretical Perspectives. New York: Routledge, pp. 17-42. 
Reese SD, Grant A and Danielian LH (1994) The structure of news sources on television: A network analysis of 'CBS News', 'Nightline', 'MacNeil/Lehrer', and 'This Week with David Brinkley'. Journal of Communication 44(2): 84-107.

Rosen J (2006) The people formerly known as the audience. Available at: http://archive.pressthink.org/2006/06/27/ppl_frmr.html.

Ryan C, Carragee KM and Schwerner C (1998) Media, movements, and the quest for social justice. Journal of Applied Communication Research 26: 165-181.

Savigny H (2002) Public opinion, political communication and the Internet. Politics 22(1): 1-8.

Schaap G (2009) Interpreting Television News. Berlin: De Gruyter.

Scheufele BT (2006) Frames, schemata, and news reporting. Communications 31: 65-83.

Singer JB, Domingo D, Heinonen A, et al. (2011) Participatory Journalism: Guarding Open Gates at Online Newspapers. Chichester, UK: Wiley.

Smith J, McCarthy JD, McPhail C, et al. (2001) From protest to agenda building: Description bias in the media coverage of protest events in Washington, D.C. Social Forces 79(4): 1397-1423.

Snow DA and Benford RD (1992) Master frames and cycles of protest. In: Morris A and Mueller C (eds) Frontiers in Social Movement Theory. New Haven, CT: Yale University Press, pp. 133-155.

Springer N and Pfaffinger C (2012) Why users comment online news and why they don't. Paper presented at the 62nd ICA Annual Conference, 23-28 May 2012, Phoenix, AZ.

Springer N (2014) Beschmutzte Öffentlichkeit? Warum Menschen die Kommentarfunktion auf Onlinenachrichtenseiten als öffentliche Toilettenwand benutzen, warum Besucher ihre Hinterlassenschaften trotzdem lesen, und wie die Wände im Anschluss aussehen [Smudged Public Sphere? Why People Use the Commentary Function on Online News Pages as a Public Toilet Wall, Why Visitors Read Their Remains Nevertheless, and How the Walls Look Thereafter]. Berlin: LIT.

Tenenboim-Weinblatt K (2008) Fighting for the story's life: Non-closure in journalistic narrative. Journalism 9: 31-51.

Tewksbury D, Jones J, Peske MW, et al. (2000) The interaction of news and advocate frames: Manipulating audience perceptions of a local public policy issue. Journalism \& Mass Communication Quarterly 77(4): 804-829.

Thévenot L, Michael M and Claudette L (2000) Forms of valuing nature: Arguments and modes of justification in French and American environmental disputes. In: Lamont M and Thévenot L (eds) Rethinking Comparative Cultural Sociology: Repertoires of Evaluation in France and the United States. Cambridge: Cambridge University Press, pp. 229-272.

Van Gorp B (2005) Where is the frame? Victims and intruders in the Belgian press coverage of the asylum issue. European Journal of Communication 20(4): 484-507.

Van Zoonen EA (1992) The women's movement and the media: Constructing a public identity. European Journal of Communication 7: 453-476.

Voakes PS, Kapfer J, Kurpius D, et al. (1996) Diversity in the news: A conceptual and methodological framework. Journalism \& Mass Communication Quarterly 73(3): 582-593.

Wessler H (1999) Öffentlichkeit als Prozess: Deutungsstrukturen und Deutungswandel in der deutschen Drogenberichterstattung [Public Sphere as a Process: Interpretative Structures and Changing Interpretations in the German Media Coverage About Drugs]. Opladen: Westdeutscher Verlag.

Wetherell M and Potter J (1988) Discourse analysis and the identification of interpretative repertoires. In: Antaki C (ed.) Analysing Everyday Explanation: A Casebook of Methods. London: SAGE, pp. 168-183.

Zaller JR and Chiu D (1996) Government's little helper: U.S. press coverage of foreign policy crises, 1945-1991. Political Communication 13(4): 385-405. 